\title{
Innovative free-form glass fiber reinforced concrete (GRC) panel
}

\author{
Innovador panel de forma libre de hormigón reforzado con fibra de vidrio (GRC)
}

Estéfana Castañeda Vergara (Main and Corresponding Author)

Departamento de Construcción y Tecnología Arquitectónicas

Universidad Politécnica de Madrid (Spain)

estefanacastaneda@gmail.com

\section{Benito Lauret Aguirregabiria}

Departamento de Construcción y Tecnología Arquitectónicas Universidad Politécnica de Madrid (Spain)

benito.lauret@upm.es

\section{Juan Miguel Lirola Pérez}

Departamento de Construcción y Tecnología Arquitectónicas Universidad Politécnica de Madrid (Spain)

juanmiguel.lirola@gmail.com

\section{Graciela Ovando Vacarezza}

Departamento de Construcción y Tecnología Arquitectónicas Universidad Politécnica de Madrid (Spain)

graciela.ovando@upm.es

Manuscript Code: 821

Date of Acceptance/Reception: 02.12.2017/20.10.2016

DOI: $10.7764 /$ RDLC.16.3.479

\begin{abstract}
This paper focuses on the manufacture of architectural free-form GRC panels with 3D printed internal grid. Since double-curvature formworks and molds could account for up to 40 to $80 \%$ of the production cost of the pieces, especially in small series product, avoiding these casting requirements is a highly attractive prospect economically. In this paper a feasible, moldless, 3D printing method combined with a Glass Reinforced Concrete alternative is considered as a solution to this drawback. Furthermore, it explores current methods involved in free-form GRC panel production, as well as the approach to additive manufacturing as an alternative for eluding formworks. Thus, GRC and 3D printing processes are described in detail and then evaluated as complementary techniques in this hybrid technology.
\end{abstract}

Key words: Glass Fiber Reinforced Concrete, 3D printing, free-form architecture, no mold process, doubly-curved panel.

Resumen

Este artículo se centra principalmente en la fabricación de paneles arquitectónicos de forma libre de GRC, con una malla interna impresa en 3D. Debido a que los moldes y los encofrados de doble curvatura representan entre el 40 al $80 \%$ del precio de producción de los paneles, la opción de evitar el uso del molde, especialmente en pequeñas series, es una idea muy atractiva económicamente. Por lo tanto, para resolver dicho inconveniente, se presenta un método fiable, sin necesidad de molde, con impresión 3D, y combinando con hormigón reforzado con fibra de vidrio. Además, se exploran los métodos actuales que están involucrados en la producción de paneles de GRC, así como también la aproximación de la manufactura aditiva, como una alternativa para evitar los encofrados. Los procesos de GRC y de impresión 3D son descritos en detalle, y posteriormente evaluados como técnicas complementarias en esta tecnología híbrida.

Introduction

Free-form architecture is one of the most significant trends in contemporary architecture. In the digital age, sophisticated computer programs are easily capable of generating complex 3D designs. Nevertheless, such sinuous virtual pieces are difficult to produce, expensive, time consuming and require highly qualified labor. Moreover, double-curvature panels frequently have to be manufactured as a unique piece, producing each one as an individual mold (Pronk, Rooy, \& Schinkel, 2009).

3D printing is a novel process in the construction industry and has many advantages, such as being a tool-less process, producing individual components and allowing a great freedom of geometry (Castañeda, Lauret, Lirola, 
\& Ovando, 2015), which would not be economically sustainable with traditional manufacturing techniques (Hauschild \& Karzel, 2011).

This paper proposes an innovative approach that allows the production of custom one-off GRC free-form panels. Experimental prototypes are presented to prove the feasibility of this proposal. Using 3D printing processes to provide the form and GRC as a reinforcement layer, the manufacturing of complex double-curved panels is achieved more efficiently and economically. This reduction in cost comes from the customization of every piece, since no tooling or molding is required.

\section{Problem description}

Recent architectural projects increasingly incorporate free-form façade elements, easily achievable by current computer drawing tools. Design free-form pieces usually leads to surfaces hardly or impossible to reach by repetitive panel addition. This means that a non-negligible number or unique panels will be needed to build properly these façades. The high cost of unique panels comes from the impossibility to divide mold cost by the series produced.

The standard production of free-form GRC pieces involves manufacturing molds for every single part of the building's envelope frequently using Computer Numerical Control (CNC) milling methods. These techniques are of great relevance within free-form panel manufacture, due to their ability to create personalized architectural forms using typical construction materials (Naboni \& Paoletti, 2015). Nevertheless, the material waste and the intensive labor can be considered major drawbacks if milling an individual component from a block of solid material brings no decisive added value to the manufacturing process (Hauschild \& Karzel, 2011).

Since mold manufacturing often determines the cost of the panel, there are strong economical reasons to establish an innovative method that avoids the need for casting in order to reduce costs.

State of the Art

The ideal seamless transition from design to construction is now guaranteed by the use of digital models, created by the design office and then used in manufacturing processes.

A high percent of planning, calculation, drawing, optimization, and rendering in construction is based on digital data. Along with this comes increasing direct interface between the computerized design process and the physical implementation (Hauschild \& Karzel, 2011). Currently, different processes are being explored to find new construction efficient methods of translating the designed architecture to a real building.

3D digital modeling software based on NURBS (Non-Uniform Rational B-Splines) has opened a universe of complex forms that were, until the appearance of CAD /CAM technologies, very difficult to conceive, develop and represent, let alone manufacture (Kolarevic, 2005). In this context, the production of complex panels is possible by means of computer numerically controlled (CNC) manufacturing processes.

Some renowned buildings as The Heydar Aliyec Centre, the Kunsthaus in Graz, or the Sage Gateshead are great architectural icons of our times, designed with complex forms that have been manufactured using digital molding processes. In this paper, the writers review the latest methods that can be applied on the free-from architectural façade panels as the CNC forming, subtractive and additive procedures.

Some particular manufacturing free-form processes are forming procedures. Some of them include CNC punching, CNC folding, CNC bending, hydroforming, linear flow splitting, flexible roll forming and bending, thermoforming, injection molding, welding, and multi-point forming.

In this area, Formtexx (Gould, 2014), CIG (www.centralindustrygroup.com) and other R\&D groups (Lee \& Kim, 2012) (Li, Cai, Sui, \& Yan, 2002) (Cai, Li, \& Lan, 2012) (Park \& Kim, 2003) are developing technologies that can manufacture double-curvature metal panels by incorporating automobile and ship procedures. One example is the Cricket Station London (1999) by Future Systems, which was manufactured in a shipyard.

Other CNC subtractive methods include punch, lasering, waterjet, plasma arc, hot-wire, two-axis to six-axis 
milling, and multi-axial robotic lasering. These are commonly the procedures frequently used in construction, due to the manufacturing industry which has used them to mass-produce elements for conventional orthogonal geometries. Using one of these procedures, NIO Architecten designed the curved Bus Stop in Hoofddorp, Netherlands. The structure was manufactured from polystyrene foam pieces using the hot-wire method. A layer of GRP coating protects its surface and the total measurements of the construction are $50 \mathrm{~m} \times 10 \mathrm{~m} \times 5 \mathrm{~m}$. The construction cost one million euros and it would have been twice if the structure had been traditionally built with concrete and steel (Hauschild \& Karzel, 2011).

Additive Manufacturing (AM) is the opposite of subtractive processes, since AM is described as adding layers of material to produce a piece, without the need for tools or preforms (tool-less). It allows an economically sustainable production of non-standard components, unlike production using traditional manufacturing techniques (Hauschild \& Karzel, 2011) (Castañeda et al., 2015).

However, AM was considered limited in building production due to the reduced size of the objects produced, and has been mainly used to manufacture mock-ups with complex geometries, such as desktop printers. Nevertheless, these assessments are changing, since the 3D printing industry is improving its machines (Buswell, Soar, Gibb, \& Thorpe, 2007) (DUS architects, 2015). Large-scale printers like BAAM (Cincinnatti Incorporated, 2015), BigRep One (Gurka, 2016), VX400 of Voxeljet, D-Shape (Dini, 2009), Contour Crafting (Khoshnevis, Hwang, Yao, \& Yeh, 2006), among others, show the feasibility of 3D printing building façade components, without the need of molds (Castañeda et al., 2015). So, time production and final costs decrease with moldless manufacture.

As an example, the MeshMould project is looking into robotic extrusion for 3D mesh structures both as a combined formwork and a reinforcement system for non-standard concrete elements. These are manufactured as continuous extrusions using an on-site Universal Robot UR5 robotic arm with a custom-built ABS filament extruder (Hack \& Lauer, 2014). The main disadvantages of this procedure are the difficulty in containing the concrete and the need for supplementary support material for complex forms. However, this example demostrates the potential of large-scale AM as an innovative but feasible manufacturing technology.

The other material of this research, GRC, has been used as a thin-walled form since its initial development in the 1970s due to its durability, relatively-light weight, weather resistance and easy moldability into specific dimensions and shapes (Henriksen, Lo, \& Knaack, 2015). In the last decade, architectural cladding systems of GRC panels have been used in several remarkable free-form buildings, including the Heydar Aliyev Cultural Center, in Baku; the King Abdullah Petroleum Studies and Research Center, in Riyadh, Saudi Arabia; the Fundation Louis Vuitton, in Paris; and the Qatar National Museum, in Doha. In all these constructions, GRC's success lies in its ability to produce many panels using a simple, cost-effective approach.

Sprayed, premixed and automated premixed methods are the most common procedures for the production of GRC. As for the different production methods for thin reinforced cement elements, they are described in (ACl 549.2R., 2004). Among the three procedures for the production of GRC, the sprayed method is the most flexible and feasible in terms of achieving different shapes and offsets. It allows for a fiberless surface coating to be sprayed, initially or finally, in order to minimize air bubbles and visible fibers on the surface of the GRC panel.

The main disadvantage of free-form GRC panels is the need for individual molds, conventionally made out of wood or steel, for each piece. Since wooden molds are usually available for flat or single curved geometries with radii $(r>0.5 \mathrm{~m})$, the wooden surface sheets must be sufficiently thin to facilitate the forming. Wooden molds are an expensive choice for one-off double curved panels (Henriksen et al., 2015). Rubber molds are an alternative choice, but a preliminary "negative" mold is needed to create the "positive" rubber mold, which, again, is not cost-effective unless there is a considerable repetition of the form.

The most used mold techniques are the static, the reusable and the flexible. For the production of free-form panels, flexible molds (FM) are an alternative (Pronk \& Houtman, 2005) (Pronk, Seffinga, el Ghazi, \& Schuijers, 2015) (Henriksen et al., 2015) (Schipper \& Grunewald, 2014), which allows for the singularity of each piece at no added cost. The performance of each panel starts with the configuration of the flexible bed to obtain the desired shape and then the concrete mixture or GRC is poured onto it. For the curing process it is necessary to keep the panel on the forming bed for at least a few hours, which slows down the procedure.

Many issues concerning flexible molds for free-form panels remain unsolved. FM can be optimized in several ways to manufacture more accurate molds. For example, settings have to be digitally, not manually adjusted, which is far from ideal when using an oven. Finish contour edges must be improved. Additionally, a feasible 
method for validating the geometry is also needed in order to predict the deformation of the flexible layer, and in doing so, prevent undersirable outcomes (Van Rijbroek, 2015).

In conclusion, free-form panel production reviewed involve sheets made of metal, GRP, GRC and other AM materials. Metal panels are of high cost and important thermal expansion coefficient. GRP is also of high cost, its durability is always compromised by UV solar radiation and has lower mechanical strength than metal and GRC. Finally, AM materials have some anisotropy behavior due to the layer deposition process, so their strength has to be improved. So, GRC is by far the best material for free-form façade purposes, due to its low thermal expansion, low cost (not considering mold), and high durability. GRC only drawback is the cost of the mold, especially in short or one-off series. Large-scale 3D printers offer a new opportunity of making an inexpensive, low material use, support plastic grid for the GRC to be sprayed over, creating the desired free-form panel.

Metodology

An innovative GRC free-form moldless panel (Figure 1) and the process cycle for off-site manufacturing is presented in this paper.

Application of thin layers of mortar over metallic meshes to conform thin façade panels is a traditional technique in building construction. In this way metallic meshes act as a reinforcement of the mortar. The idea of applying GRC over a plastic mesh comes from this basic technique, as a way to get rid of the otherwise necessary mold. Plastic can not perform as a reinforcement, because its low Young modulus, but it is not needed GRC includes its own fiber reinforcement. In this way plastic mesh acts only as a bed for the GRC to be sprayed over. But a plastic mesh of almost any surface shape, especially free form architectural surfaces, can be easily and effectively achieved by current large scale AM 3D printers. Considering 3D printing as the only additional process.

GRC panels, as factory made elements, should follow a feasible step by step process, so integration into regular production processes with minimum distortion or special required skills is of key importance. Casting GRC panels involve the use of both spraying machines and rendering skilled labor.

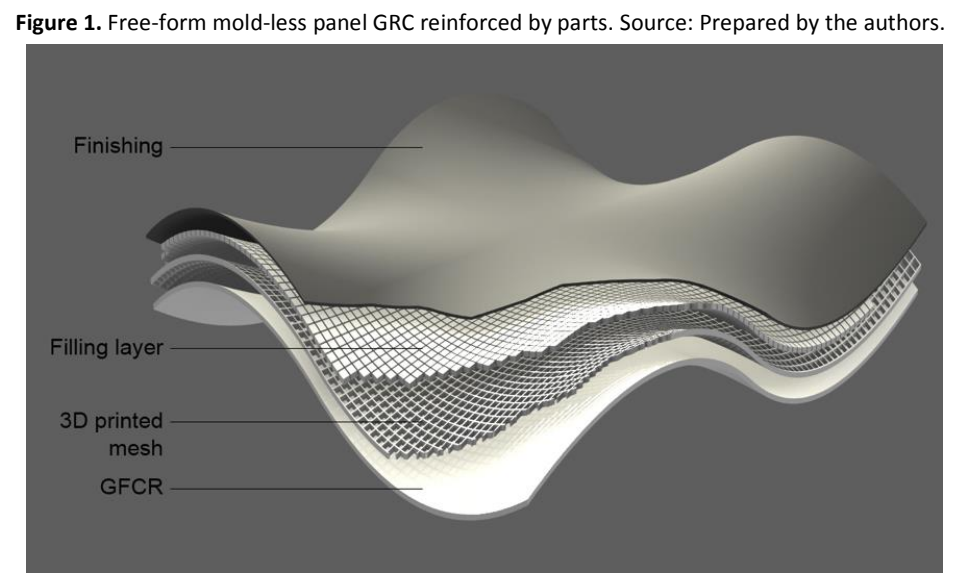

To define a proper manufacturing process two strategies can be envisaged: to spray GRC over the inner face of the plastic mesh, or to do it over the outer face. Every one has advantages and drawbacks. First strategy is more conservative, not compromising the accuracy of the external surface as any unevenness of GRC is concealed in the inner face. Then any hollow in the plastic mesh should be filled up with mortar, to allow for a very thin finishing coat. Thus keeping maximum accuracy in the achieved surface, despite the manual execution of rendering tasks. Second strategy is riskier, as long as its final accuracy depends on a perfect and constant thickness of GRC layer. Final coating should not deal with major flaws to make the process optimal. Otherwise flaw repair and correction would consume additional time and labor, seriously compromising final surface accuracy.

First strategy here defined is described below in detail.

Additive Manufacturing is a method that offers multiple advantages, such as the possibility of producing single pieces with complex shapes, and not making each manufactured item more expensive. No external tools or molds are required, making it an excellent technological option. 
The GRC is a widely known material, with high capabilities such as a self-supporting, withstand loads of wind and snow, to be outside in direct contact with the environment factors but, at the same time, continued bringing lightness. Therefore, the combination of Additive Manufacturing and GRC results in a new panel system. The thermoplastic mesh core provides the form, and a GRC layer the reinforcement. So, it becomes an element with features of a façade panel, with great lightness, small thickness and the possibility of having any shape.

To begin with, the design of the surface and the approach of the panels are described. The free-form mesh is studied and designed using CAD software, for starting in a digital environment, which will be essential in the successive 3D printing process.

This paper explains as well the development of a 3D printed plastic mesh, which manages to reproduce the geometry of the architect's design precisely and especially to minimize outer face distortions.

The GRC sprayed method, which can generate a layer on the plastic mesh's inner surface, is described. This GRC cover holds the overall strength of the panel, which is essential, since the plastic mesh does not have all the necessary performance to be a façade panel. So the unification of both parts is suitable.

Following, the procedure by which the gaps are filled with GRC or mortar, without exceeding the limit of the plastic mesh, is outlined. Additionally, this paper explains the process involving the application of a final coating, which overlays the grid on its outer face. The alteration of the final form is minimal due to the limitation of 3 millimeters in the final thickness, used to avoid deformations of the original design.

Conclusions with the constructive detailing of both the full-scale and test prototype and some alternative on-site handling procedures are presented.

\section{Description of materials}

The list of materials is as follows:

- $A B S$ : regular ABS was used to 3D print the mesh, with specification of ASTM D-638 for the type IV tensile specimens and ASTM D-5379 for the shear specimens (Cantrell, J., Rohde, S., Damiani, D., Gurnani, R., Disandro, L., Anton, J., 2011), with a thickness of $3 \mathrm{~mm}$.

- GRC: Portland cement, BL II/A-L 42, 5R and glass fiber, Cem-Fil ${ }^{\circledR}, 2.63 \mathrm{~g} / \mathrm{cm}^{3}$ density by ASTM C693, tensile strength 8-12 Mpa.

- Finish Mortar coating: cement fast-setting conforms ASTM C-1328 and ESR-2671, compressive strength 24.1 MPa.

\section{Design of the 3D mesh}

3D Modelling in CAD is a significant and necessary step to achieve the free-form GRC panel, due to production of the mesh in a 3D printer with a digital support. Thus, these complex forms need a powerful enough computer and program to model them correctly. In this case, NURBS (Non-Uniform Rational B-Splines) curves are the most suitable tools because they bring both efficiency to the drawing process of most types of complex curves and the opportunity to have parametric control over the project (Moya \& Pons, 2014).

Before producing the panel design, it is essential to generate a paneling of the free-form architectural envelope. The main difficulty is the design approach of the surface as a series of patches, called panels, which can be designed and manufactured using a selected technology. Thus, the desired aesthetic quality and surface smoothness is achieved ( Eigensatz, M., Kilian, M., Schiftner, A., Mitra, N., Pottmann, H., \& Pauly, M., 2010).

Each panel is designed with predefined dimensions using CAD software and then converted in a NURBS curved mesh. The orifices shall allow the penetration of cement mortar and GRC without spilling. The mesh acts mainly as a formwork, helping to hold the complex double-curved shape. These perforated cores can be modified through parametric feature-based modeling in order to generate a large range of alternative design solutions automatically (Turrin, Von Buelow, \& Stouffs, 2011). This is particularly useful in the early phases of the design, when it can be used to explore the correlation between different shapes and their performance.

For openings and surface coating, an edge element, which provides a limit for the poured mortar, is designed. Thus, the mortar never enters areas designed as openings nor does it overlap the edge of the panel, resulting in 
perfectly defined sides. These edge pieces or boundary elements (Figure 2) are temporary and can be removed at the end of the coating phase.

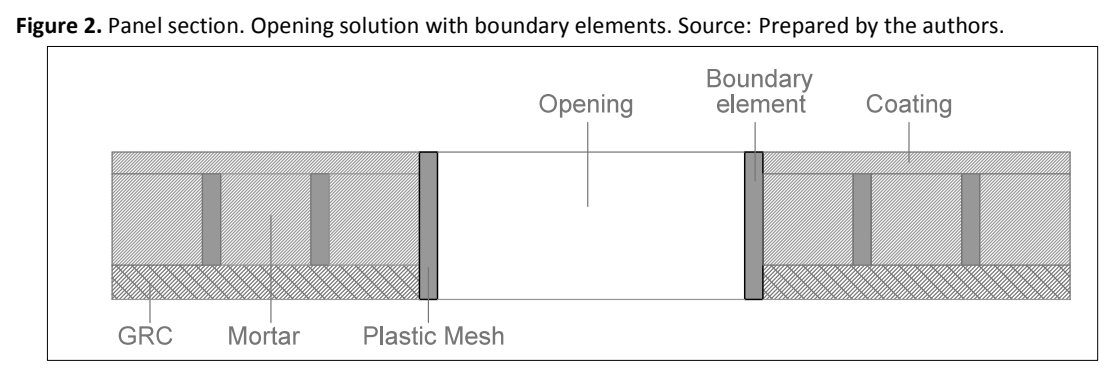

The doubly-curved form chosen for the study is a so-called "rubber surface" because it incorporates convex and concave curves, which allows the behavior of the piece to be observed from different angles. Rhinoceros ${ }^{\circledR}$ and AutoCad ${ }^{\circledR}$ were the software used to design this model. Its dimensions are $0.90 \mathrm{~m} \times 1.00 \mathrm{~m}$ and the orifices of the grid are $0.016 \mathrm{~m} \times 0.012 \mathrm{~m}$, which is $0.01 \mathrm{~m}$ thick. These dimensions are due to the capacity of the 3D printing machine $\left(1.00 \mathrm{~m}^{3}\right)$, and the gaps of the mesh are appropriate to keep in the cement mortar and the GRC, and do not let them split through the holes.

\section{D printing}

Previously to the 3D printing process, it is necessary to analyze and check the dimensions of the mesh, since the final coating, the GRC and the cement mortar increase the thickness of the panel. So, it must be considered every layer to achieve an accurate measure. Also, the printed elements as supporting material, edge pieces, among others, should be taken into account.

Once the adjusted computer data are accurate, the CAD simulation is usually exported as an STL file. This file consists of a list of triangular face coordinates, whose edges fit perfectly to form a representation of the surface of the model. The STL-file is then processed using a 3D printer dependent computer program. This software adds, where necessary, temporary support structures to aid in the building process. The whole structure is then sliced into planes and sequential lists of vectors, creating a specific file with extension G-CODE.

The generation of the codes is now automated through Computer-Aided Manufacturing (CAM) software and many 3D printers run on G-CODE files. The tool path is generated specifically for the process and is often optimized to reduce printing time. The processes generally trace the surface of the plane in a sequential order to identify the location of the solid boundaries and voids (Qiu, Langrana, Danforth, Safari, \& Jafari, 2001). This procedure converts this analysis into machine operations. Open source software for 3D printing, Repetier and Slic $3 r$, were used for the manufacturing of the prototype to convert the STL file to G-CODE.

After the 3D printer has received the machine code, the automated printing process begins, depositing layer upon layer of plastic filaments, on the printer area with an extruder, and where necessary, generating the corresponding support material. The geometry and the properties of the deposited strings cause a stepped surface and edges (Knaack, Klein, \& Bilow, 2010). Opposite to smoothness surfaces of plastic, the roughness of these steeped Surfaces and edges benefits the adherence between plastic and cement mortar and GRC.

A large-scale Prusa 3D printer, with a $0.5 \mathrm{~mm}$ interval between layers, was used to manufacture the doublycurved mesh models. Its printing area is $1.00 \mathrm{~m} \times 1.00 \mathrm{~m} \times 1.00 \mathrm{~m}$, and the thickness of the ABS filament is $3 \mathrm{~mm}$.

\section{GRC reinforcing}

One major decision in the design of the mesh was the shape and size of the grid cell. On the one hand, the cell should be a good base for the GRC, preventing the material from seeping through the holes. On the other hand, it should provide a good external surface for the proper adherence of the final coatings. Grid sizes of between five and ten millimeters have proven to work satisfactorily for both the GRC and the coating.

To begin with, the panel needs to be secured to prevent movement (Figure 3a). The process for manufacturing the panel begins by spraying GRC, cement mixed with glass-fiber, onto the inner surface of the mesh (Figure $3 \mathrm{~b}$ ). 
The alkali resistance of glass-fiber depends mainly on the content of Zirconia $\left(\mathrm{ZrO}_{2}\right)$ present in the glass, with an approximate content of $19 \%$. The fibers are chopped by the spray gun with a length of approximately $32 \mathrm{~mm}$.

Mortar is then poured onto the outer side to fill the net gaps in the net level to the upper edge of the cells in order to maintain the shape of the panels. Subsequent trowelling helps remove excess material (Figure 3c). The materials are then left to harden until the next day (Figure $3 \mathrm{~d}$ ). Finally, the units are covered with polyethylene and allowed to cure for approximately 7 days.

Figure 3. Manufacturing process of a GRC panel. a. Fixed mesh. b. GRC sprayed. c. Removing excess material. d. Trowelling and finish job. Source: Prepared by the authors.
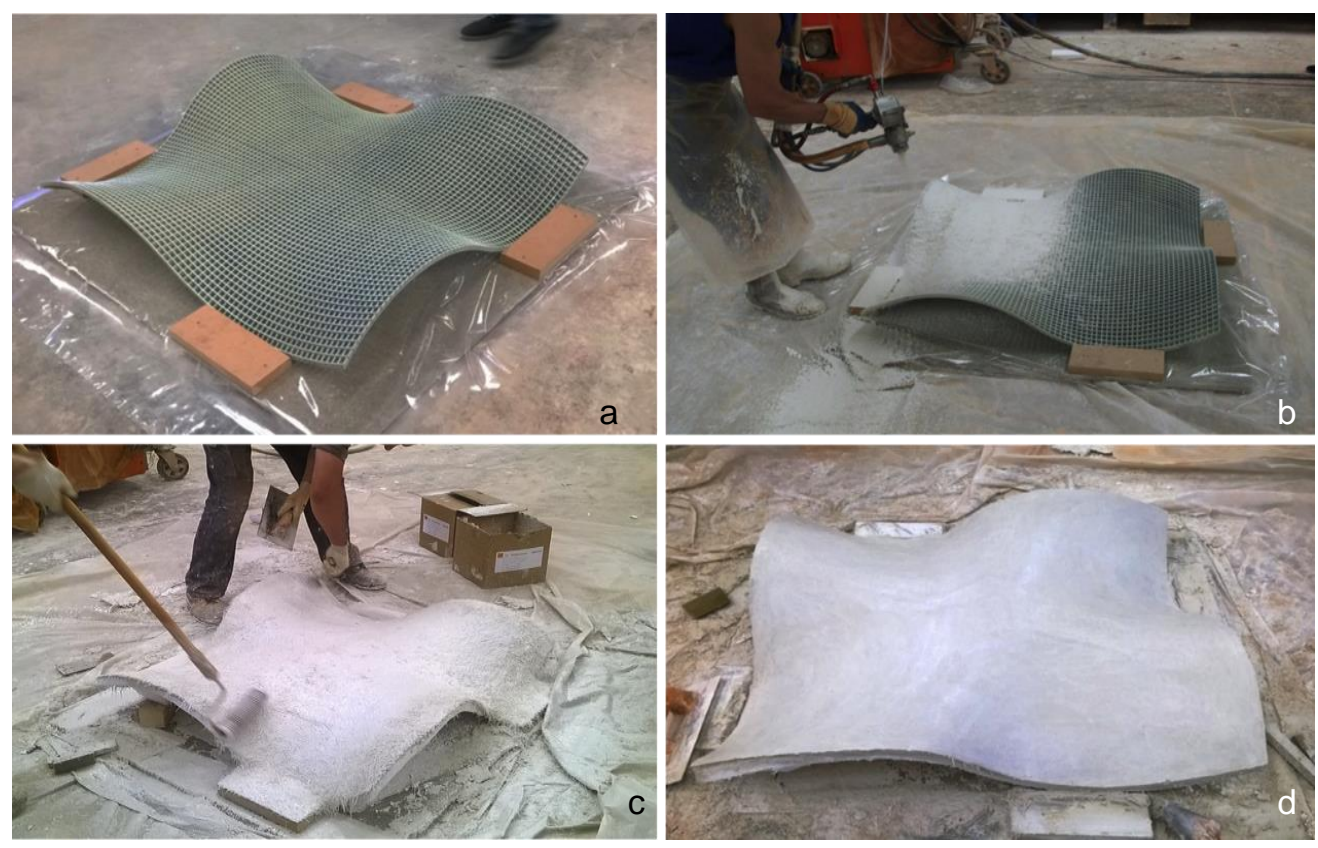

A $15-20 \%$ of water content must be maintained for an optimal mortar performance to ensure the concrete's workability (ACl 549.2R., 2004) (GRCA, 2014). In addition, when poured, the mortar should set to prevent adequate suitable bonding with both the plastic grid and the GRC. These properties can be obtained by adding a retarder or accelerator as required in each case. The thixotropic behavior of concrete is highly beneficial on vertical surfaces and can be further intensified by adding thixotropic agents.

As regards the adhesion between the cement and the plastic, recent developments in cement-based industrial mortars have made a wide range of specialized mortars that show excellent adherence to several plastics (Saikia $\&$ De Brito, 2012) commercially available. The use of a fast curing mortar, especially in complex doubly-curved panels, is essential. However, the 3D grid design can be customized to achieve an even more monolithic nature, e.g. making it hollow-walled.

\section{Final coating}

The final finish is achieved through conventional techniques, such as painting, rendering, polishing or plastering. In order to achieve the aesthetic demand for a monolithic and continuous appearance, it is possible to close the joint between adjacent panels. Furthermore, this could be achieved using existing building industry solutions that offer a certain degree of movement between panels, such as mortar, sealant, gasket and compressible foam. However, the complex curvatures of free-form panels can be a difficult surface to finish.

Alternatively, the outer surface is pre-treated with lathwork, which is used to build elements with a base suitable for the proposed plaster system. The base is covered with a plastic net (alkali-resistant material), through which an improvement in the bonding of the plaster is attempted. Thus, this net is used to join the panels in the finishing stage and provide a continuous surface without evident joints.

To prove the feasibility of the proposed method, a previous test prototype has been printed and coated manually with cement mortar. Furthermore, progressive filler and sanding finishing iterations allow for a very accurate and shiny, automobile-like surface, as shown in Figures 4 and 5. 
Figure 4. Mesh coated with cement mortar. Source: Prepared by the authors.

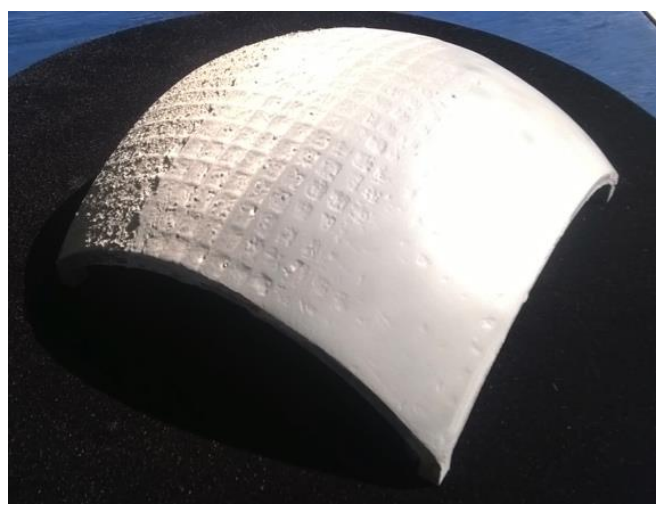

Figure 5. Panel progressive finishing, from filler and sanding to a shiny, automobile-like surface. Source: Prepared by the authors.

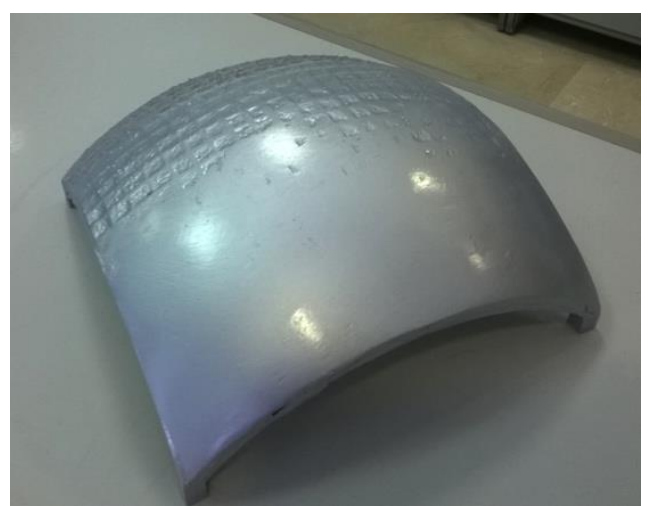

Results and Conclusions

Manufacturing free-form architectural panels is often expensive, time-consuming and skilled-labor-intensive. The proposed 3D printed reinforcing mesh allows for an improved production of free-form GRC architectural panels.

The production of curved panels is mostly based on molds. Since the cost of mold fabrication often dominates the panel cost (Eigensatz et al., 2010) around $40-80 \%$ of the final panel price. Recent digital advances allow for complex façade panel fabrication at a reasonable price, by means obviating the use of molds as the $3 \mathrm{~d}$ printing process reviewed in this paper.

The main objective of the prototypes in this paper is to prove the feasibility of manufacturing a 3D printed + GRC double-curvature panel. No expensive or sophisticated new equipment is needed - only a prototype of a large 3D printer. Oversized samples have already been developed, showing the feasibility of large-scale building elements. The four-step production process, comprising 3D printing, reinforcing, filling and coating, allows for the easy manufacture of a custom CAD-designed architectural panel.

The materials involved are widely available. Specifically plastic, the main additive material for printing, can come from the recycling of a wide variety of items (Soloaga, Oshiro, \& Positieri, 2014). Since the amount of material needed is reduced to a minimum, such an approach has a great potential for resource efficiency. Furthermore, Glass Reinforced Concrete is also an efficient material per façade surface unit, appropriate for the manufacture of free-form lightweight architectural panels due to its mechanical properties, which are ideal for providing a thin but sturdy reinforcing core.

There are several methods available to produce reliable free-form, custom one-off architectural panels, such as Formtexx or Contour Crafting. The former is a very high quality metal forming process for sophisticated metal façades, while the latter produces a coarse, thick mortar mass for structural or low quality finishes. Additionally, the MeshMould project can print plastic meshes for double-curvature panels. Nevertheless, the cement-based method proposed in this paper is intended to be more cost-efficient than Formtexx and more accurately shaped and lightweight than the MeshMould project.

The 3D printed mesh assures the required adherence for both the reinforced mortar core and the external coating. Both materials can be applied in several steps, from rougher to smoother layers of mortar, filler and paint. The mock-up presented took approximately 28 hours to print. This is considered a long time to an industrial process, but it is still a very reliable option compared to the seven days that rubber molds usually take for its manufacture.

As shown in laboratory samples, a variety of finishes can be achieved, ranging from a plain white stucco appearance to a glossy, metallic automotive-like finish.

There is room for research and improvement, beyond the scope of this article, before the panel can be commercialized for use. These include improving the printing speed and testing both the adhesion between 
cement and plastic and the strength of the panel. Future research, both experimental and analytical, could be conducted in the areas of construction and finishes, as well as in the integration of computer software for paneling, mesh conversion and structural analysis. The work undertaken in this article confirms the feasibility of this GRC panel and is the first step towards the realization of the full production of architectural panels.

Acknowledgements

We are grateful to Prefabricados Ponce S.L. for providing us with the material and specialized labor on sprayed GRC, and the physical space to accomplish our objectives, and to CONACYT (Mexico) for the doctoral scholarship.

ACI 549.2R. (2004). Report on Thin Reinforced Cementitious Products. ACl Committee 549.

Buswell, R., Soar, R., Gibb, A., \& Thorpe, A. (2007). Freeform Construction: Mega-scale Rapid Manufacturing for construction. Automation in Construction, 16(2), 224-231. http://doi.org/10.1016/j.autcon.2006.05.002

Cai, Z.-Y., Li, M.-Z., \& Lan, Y.-W. (2012). Three-dimensional sheet metal continuous forming process based on flexible roll bending: Principle and experiments. Journal of Materials Processing Technology, 212, 120-127. http://doi.org/10.1016/j.jmatprotec.2011.08.014

Cantrell, J., Rohde, S., Damiani, D., Gurnani, R., Disandro, L., Anton, J. (2011). Experimental Characterization of the Mechanical Properties of 3D-Printed ABS and Polycarbonate Parts. University of Florida.

Castañeda, E., Lauret, B., Lirola, J. M., \& Ovando, G. (2015). Free-form architectural envelopes: Digital processes opportunities of industrial production at a reasonable price. Journal of Facade Design and Engineering, 3(1), 1-13. http://doi.org/10.3233/FDE-150031

Cincinnatti Incorporated. (2015). BAAM. Retrieved from http://www.e-ci.com/baam/

Dini, E. (2009). D-SHAPE - The 21st century revolution in building technology has a name.

DUS architects. (2015). 3D Print Canal House. Retrieved July 2, 2016, from http://www.dusarchitects.com/

Eigensatz, M., Kilian, M., Schiftner, A., Mitra, N., Pottmann, H., \& Pauly, M. (2010). Paneling Architectural Freeform Surfaces. In ACM Trans.Graph. SIGGRAPH '10 (Vol. 29, p. 45:1-45:10). New York. http://doi.org/10.1145/1833351.1778782

Gould, J. (2014). Formtexx. Retrieved from http://www.formtexx.com/index.html

GRCA. (2014). GRC Façade Cladding. Retrieved from http://www.grca.org.uk/grc-projects/grc-facade-cladding.php

Gurka, R. (2016). BigRep. Retrieved from https://bigrep.com/

Hack, N., \& Lauer, W. (2014). Mesh Mould. Robotic fabrication for non-standard concrete constructions. FCL Magazine Special Issue. Robotic High Rises, (3), 30-55.

Hauschild, M., \& Karzel, R. (2011). Digital Processes: Planning, Designing, Production. Birkhäuser.

Henriksen, T., Lo, S., \& Knaack, U. (2015). An innovative approach to manufacture thin-walled glass fibre reinforced concrete for tomorrow's architectural buildings envelopes with complex geometries. Journal of Building Engineering. http://doi.org/10.1016/j.jobe.2015.09.006

Khoshnevis, B., Hwang, D., Yao, K.-T., \& Yeh, Z. (2006). Mega-scale fabrication by contour crafting. International Journal of Industrial and Systems Engineering, 1(3), 301-320. http://doi.org/http://dx.doi.org/10.1504/IJISE.2006.009791

Knaack, U., Klein, T., \& Bilow, M. (2010). Rapids. Imagine 04. Rotterdam: 010 Publishers.

Lee, G., \& Kim, S. (2012). Case Study of Mass Customization of Double-Curved Metal Façade Panels Using a New Hybrid Sheet Metal Processing Technique. Journal of Construction Engineering and Management, 138(11), 1322-1330. http://doi.org/10.1061/(ASCE)CO.1943-7862.0000551

Li, M. Z., Cai, Z. Y., Sui, Z., \& Yan, Q. G. (2002). Multi-point forming technology for sheet metal. Journal of Materials Processing Technology, 129(1-3), 333-338. http://doi.org/10.1016/S0924-0136(02)00685-4

Moya, Q., \& Pons, O. (2014). Improving the design and production data flow of a complex curvilinear geometric Glass Reinforced Concrete façade. Automation in Construction, 38, 46-58. http://doi.org/10.1016/j.autcon.2013.10.025

Naboni, R., \& Paoletti, I. (2015). Advanced Customization in Architectural Design and Construction. BOOK, Springer International Publishing. http://doi.org/10.1007/978-3-319-04423-1

Park, J. J., \& Kim, Y. H. (2003). Fundamental studies on the incremental sheet metal forming technique. Journal of Materials Processing Technology, 140, 447-453. http://doi.org/10.1016/S0924-0136(03)00768-4

Pronk, A., \& Houtman, R. (2005). Making Blobs with a Textile Mould. In E. Oñate (Ed.), Textile Composites and Inflatable Structures 3, 305322. Springer. http://doi.org/10.1007/1-4020-3317-6 
Pronk, A., Rooy, I. Van, \& Schinkel, P. (2009). Double-curved surfaces using a membrane mould. Proceedings of the International Association for Shell and Spatial Structures (IASS) Symposium 2009, Valencia, (October), 618-628.

Pronk, A., Seffinga, A., el Ghazi, H., \& Schuijers, N. (2015). Flexible mould by the use of spring steel mesh. In Proceedings of the International Association for Shell and Spatial Structures (IASS). Amsterdam.

Qiu, D., Langrana, N. A., Danforth, S. C., Safari, A., \& Jafari, M. (2001). Intelligent toolpath for extrusion-based LM process. Rapid Prototyping Journal, 7(1), 18-24. http://doi.org/10.1108/13552540110365126

Saikia, N., \& De Brito, J. (2012). Use of plastic waste as aggregate in cement mortar and concrete preparation: A review. Construction and Building Materials, 34, 385-401. http://doi.org/10.1016/j.conbuildmat.2012.02.066

Schipper, H. R., \& Grunewald, S. (2014). Efficient material use through smart flexible formwork method. In ECO-Crete: International Symposium on Environmentally Friendly Concrete (61-67). Reykjavik, Iceland. Retrieved from http://resolver.tudelft.nl/uuid:5f767d7f6ad1-4e37-9efc-1817e9561274

Soloaga, I. S., Oshiro, A., \& Positieri, M. (2014). The use of recycled plastic in concrete. An alternative to reduce the ecological footprint. Journal of Construction, 13(3), 19-26. http://doi.org/http://dx.doi.org/10.4067/S0718-915X2014000300003

Turrin, M., Von Buelow, P., \& Stouffs, R. (2011). Design explorations of performance driven geometry in architectural design using parametric modeling and genetic algorithms. Advanced Engineering Informatics, 25(4), 656-675. http://doi.org/10.1016/j.aei.2011.07.009

Van Rijbroek, E. (2015). Fluid Mould. Eindhoven University of Technology. 